\title{
Contract Management and Disputes in the Construction Industry
}

\author{
Ruveyda Komurlu \\ Department of Architecture, Architecture and Design Faculty, Kocaeli University \\ PO box 34662, Istanbul, Turkey \\ E-mail: ruveydakomurlu@gmail.com \\ Kubra Yeni \\ Department of Architecture, Institute of Science, Kocaeli University \\ PO box 54200, Sakarya, Turkey \\ E-mail: kubra.yeni@outlook.com
}

\begin{abstract}
The construction industry is an important business area where multidisciplinary efforts are performed under a complex structure. It provides the majority of national income for a country's economy. Because of its complex structure, planning, organization and definition of the parties should be conducted properly. Contracts are legal documents that bind parties and define their rights, authorizations and responsibilities. They regulate the relationship between the parties from the design until the completion of the project. In order for projects to meet the target schedule, budget and quality, contracts should be comprehensive to provide clarification to various aspects. For avoiding misinterpretations and contradictions, they need to be written in an open, clear and comprehensible language. Deficiencies and lack of detail cause disagreements between the parties. For the success of a project, site performance is as important as the contract. Contract administration, through timely interference with deficiencies and errors, avoids divergences from project targets such as schedule and budget. This study, through literature review, focuses on the concept of the construction contract, project and contract administration, the importance of construction contracts and the disputes between the parties. It aims to provide information to persons, companies and institutions interested in the subject.
\end{abstract}

Keywords: Construction contracts, Contract management, Project management, Dispute

DOI: $10.7176 / \mathrm{JSTR} / 5-11-09$

\section{İnşaat Sektöründe Sözleșme Yönetimi ve Uyuşmazlıklar}

\begin{abstract}
Özet
İnşaat sektörü birçok disiplinin bir arada çalıştı̆̆ı, karmaşı bir yapısı olan ve ülke ekonomisinde ulusal gelirin büyük kısmını oluşturan önemli bir iş koludur. Kompleks yapısı itibarıyla projelerde planlama, organizasyon ve katılımcıların görev tanımlarının iyi yapılmış olması gerekir. Sözleşmeler tarafları birbirine bağlayan, katılımcıların hak, yetki ve sorumluluklarını belirleyen hukuki belgelerdir. Sözleşmeler projenin tasarım aşamasından tamamlanmasına kadar tüm süreçlerde taraflar arasındaki ilişkileri düzenler. İnşaat sektöründe projenin hedeflenen süre, maliyet ve kalitede tamamlanabilmesi için sözleşmelerin farkı konulara açıklık getirebilen kapsamlı bir yapıda olması gerekmektedir. Sözleşmeler yanlış anlaşılmalara ve çelişkilere sebebiyet vermeyecek şekilde açık, yalın ve anlaşılır bir dille yazılmalıdır. Sözleşme dokümanlarında eksiklikler, detaylandırılmamış hükümler taraflar arasında anlaşmazlıklara yol açmaktadır. Projenin başarısı için sözleşmelerin önemi kadar saha uygulamasının doğru ve eksiksiz gerçekleștirilmesi de önemlidir. Sözleșme yönetimi sayesinde, eksik ve yanlış uygulamalara zamanında müdahale edilerek süre, maliyet aşımı ve projenin kişisel yaklaşım farklılıkları sebebi ile hedeflerinden uzaklaşması önlenir. Bu çalışmada literatür taraması yapılarak projenin tüm süreçlerine etki eden inşaat sözleşmesi kavramı, inşaat sektöründe proje yönetimi ve sözleşme yönetimi, inşaat sözleşmelerinin önemi ile taraflar arasındaki uyuşmazlıklar konuları incelenmiștir. Bu çalışmanın sektörde bu konu ile ilgilenen kişi, kurum ve kuruluşlara bilgi sağlaması ve konuyla ilgili çalışma yürüteceklere ışık tutması amaçlanmıştır.
\end{abstract}

Anahtar Kelimeler: İnşaat sözleşmeleri, Sözleşme yönetimi, Proje yönetimi, Uyuşmazlıklar

71 | P a g e

www.iiste.org 


\section{Giriş}

Sözleşme sözlükteki anlamıyla "sözlü anlaşma" demektir. Bir anlaşmadan bahsedebilmek için en az iki tarafın olması gerekmektedir. Sözlü yapılan bu anlaşmaların, taraflarca unutulmalarını ve yanlış anlaşılmalarını önlemek için yazılı belgelere dönüştürülmesi gerekmektedir. Bu nedenle teknik anlamda sözleşme, söz konusu işi gerçekleştirirken tarafların görev, sorumluluk, hak ve yetkilerini içeren yazılı belgeler olarak tanımlanmaktadır (Öcal, 2014). Sözleşmeler tarafların karşılıklı ilişkilerini düzenleyerek birbirlerine bağladığı hukuki belgeler olup literatürde akit, kontrat, bağıt ya da mukavele kelimeleri ile de ifade edilmektedir.

Çalışma kapsamında çeşitli kaynaklar taranmış olup inşaat sözleşmeleri, sözleşme yönetimi ve uyuşmazlık konuları ele alınmıştır. Bu bağlamda inşaat sözleşmelerinin önemi, içeriği, dokümanları, sözleşmelerde risk faktörü, sözleşme yönetimi ve proje yönetiminin önemi irdelenmiştir. Son olarak uyuşmazlık sebepleri ve çözüm yöntemleri incelenmiştir.

\section{2. İnşaat Sektöründe Sözleşmeler}

İnşaat sözleşmesi, iş sahibinin ödemeyi taahhüt ettiği bir bedel karş1lığında yüklenicinin yapı eseri meydana getirip teslim ettiği sözleşmelerdir (Kurt, 2005). Yasalarda inşaat sözleşmeleri başlı̆̆ altında bir düzenleme bulunmamaktadır. Borçlar Kanunu'nun 470.-486. maddeleri arasında düzenlenmiş olup "eser sözleşmeleri" kapsamında incelenmektedir. İnşaat sözleşmeleri her iki tarafa da borç yüklemektedir İş sahibi bir bedel ödemeyi borçlanırken, yüklenici de yapı eseri meydana getirmeyi borçlanmaktadır. Günümüzde inşaat sektörü karmaşık bir yapıya sahip olup birçok mesleki disiplinin bir arada çalışmasını gerektirmektedir. Birbirini tanımayan kişiler ya da kurumların ilk kez birlikte çalışması, çıkar çatışmaları, adil paylaşılmayan riskler, süre, maliyet ve bilgi eksikliği gibi etkenler tarafların sağlıklı iletişim kurmalarını engelleyerek büyük bir belirsizliğe sebep olmaktadır (Korkmaz, 2004). Tarafların bu iş ilişkisinden memnun olmaları için temeli hukuk olan bir anlaşma gerçekleştirilmelidir ve bu anlaşmalar inşaat sözleşmeleridir. İnşaat sözleşmeleri, yapım süreci içinde taraflar arası belirsizlikleri yok ederek görev, yetki ve sorumlulukları, risklerin gerçekleşmesi halinde neler yapacakları ya da yapmayacaklarını tanımlayarak doğabilecek anlaşmazlıkları önler. Her proje yapılacağı yer, koşullar, iklim, ve sunulan olanaklar açısından tek ve özgündür. Bu yüzden sözleşmeler özel sektör ya da kamu sektöründe her proje için ayrı ayrı düzenlenmek zorundadır.

Sözleşme taraflarının metni farklı yorumlaması yani farklı anlamlar çıkarması projede eksiklere, hatalara ve anlaşmazlıklara sebep olmaktadır. Bu yüzden sözleşme hazırlanırken dilin yanlış anlaşılmalara sebebiyet vermeyecek şekilde açık, net ve anlaşılır olmasına; maddeler arasında tekrarlar olmamasına; detaylı ve kapsamlı olmasına ve yasalara uygun olmasının sağlanması gereklidir (Korkmaz, 2004). Eğer sözleşmenin yorumunda taraflar arasında bir şüphe varsa çözüm için mahkemeye başvurmak zorunda kalınabilir. Herhangi bir hükümdeki belirsizlik durumunda yorum, metni hazırlayan tarafın aleyhine olacak şekilde yapılmaktadır. Çünkü metni hazırlamanın sorumluluğunu taşır ve belirsiz hükümlerden kendini koruma şansı daha yüksektir (Yurt, 2005). Taraflar arasında sorumlulukların, görevlerin, hak ve yetkilerin, risk dağılımının adaletli olabilmesi için sözleşmeyi birlikte hazırlamaları en sağlıklısıdır.

\section{1. İnşaat Sektöründe Proje Yönetimi ve Sözleşme Yönetimi}

Proje yönetimi, projenin başlangıç aşamasından tamamlanmasına kadar olan tüm evrelerinde kalite, süre ve maliyetin denetim altında tutularak en etkili yönetim tekniklerinin kullanıldığı profesyonel yönetim sürecidir (Gedik, 2003). Proje yönetimi çok eski dönemlerden beri kullanılmaktadır ancak bugünkü temelleri 1950'li yıllarda atılmıştır (Timurlenk, 2018). Projelerin tekrarlanamaz niteliği, büyüklüğünün ve karmaşıklığının teknolojik gelişmelerle birlikte giderek artması ve rekabet ortamının oluşması doğru planlamayı gerektirmektedir. Bu da yönetim tekniklerinin geliştirilmesine sebep olmuş ve proje yönetimini vazgeçilmez kılmıştır.

Proje yönetiminin başarılı olabilmesi için belirlenen ana fonksiyonlar, sonradan planlama, organizasyon, liderlik etme ve kontrol etme olmak üzere 4 ana madde altında toplanmıştır (Timurlenk, 2018). Bu 4 madde başarılı proje yönetimlerinde en önemli şeyin planlı yönetim olduğunu göstermektedir. Projenin başarılı bir şekilde yürütülebilmesi, sözleşmenin proje yönetim prensipleri göz önüne alınarak hazırlanmış olmasına bağlıdır. Sözleşmeyi proje yönetimi açısından incelemeye geçmeden önce sözleşme yönetimi kavramını tanımlamak gerekir.

İnşaat projesinin sözleşmeye uygun olup olmadığının kontrol edilmesine sözleşme yönetimi denir. Sözleşme yönetimi, proje yönetim süreci içerisinde süre, maliyet ve kapsam kısıtları açısından yüklenicinin kontrol edilerek istenen kalite düzeyini elde etmek üzere mevcut kaynaklardan en verimli şekilde faydalanılmasını sağlar. Bu sebeple, sözleşme yönetimi, bir projenin başarıya ulaşması için büyük öneme sahiptir (Kurt, 2005).

72 | P a g e 
Sözleşmeler proje yönetimi ve diğer unsurların nasıl uygulanacağını belirterek kişisel yaklaşımların farklılığı sebebi ile projenin hedeflerinden uzaklaşmasını önler ve tarafların iş ilişkilerini disipline eder (Gedik, 2003). Uygulamada sözleşme sadece işin başlaması için zorunluluk olan belgeler olarak algılanmaktadır ancak projenin her aşamasında önem taşımaktadır (Korkmaz, 2004). Projeye ait sözleşme maddelerinin uygulanması süreci, sözleşme yönetimini etkin kılar ve işin başlangıç noktasından teslimine kadarki tüm süreçleri kapsar.

Sözleşmelerin iyi yönetilebilmesi için her bir maddenin iyi analiz edilip doğru yorumlanması gerekmektedir (Kurt, 2005). Sözleşmeye uymayan, eksik ya da yanlış yapılan yerlere zamanında müdahale edilerek süre ve maliyet aşımı ile anlaşmazlıklar engellenebilir.

Sözleşme yönetiminde amaç projenin sözleşmeye uygun yürütülerek teslim edilmesidir. Bu teslim de ancak başarılı bir proje yönetiminin olmasıyla mümkündür. Dolayısıyla sözleşme yönetimi ve proje yönetimi birbirinden bağımsız iki kavram değildir. Sözleşme yönetimi, proje yönetiminin bir parçasıdır ve tüm verilerini proje yönetim süreçlerinden alır (Yurt, 2005).

Dünya'da Amerikalı Mimarlar Birliği (AIA), ABD İnşaat Yöneticileri Birliği (CMAA), Proje Yönetimi Enstitüsü (PMI) gibi kurumların sözleşme yönetimini savundukları ancak farklı şekillerde ele aldıkları görülmüştür. PMI ve CMAA gibi kurumlar sözleşme yönetimini proje yönetimi ile bütünleşik ele alırken, AIA gibi kurumlar daha geleneksel bir yaklaşımla ele aldığı görülmüştür. Ancak kurumların ortak görüşü sözleşmelerin imzalanmasından teslim edilme sürecine kadar yapılan işlerin sözleşme hükümlerine uygunluğunun sağlanmasıdır (Yurt, 2005).

\section{2. İnşaat Sözleşmelerinin Önemi}

İnşaat projelerine dahil olan çeşitli katılımcıların, proje ve uygulanması ile ilgili bilgileri içeren sözleşmeyi doğru anlayabilmesi önemlidir. Her katılımcının maddelerden aynı anlamı çıkarması için sözleşmelerin açık, yalın bir dil ile detaylı olarak hazırlanması gerekmektedir. Günümüzde inşaat yapılarının büyümesi ve karmaşı olması, iyi bir planlama ve organizasyon yapmayı gerektirmektedir. İnşaat sözleşmeleri kim tarafından hazırlanırsa hazırlansın içeriğinde belli temel konuları barındırmak zorundadır. Bu konular aşağıda verilmiştir (Yalçın, 2004):

- Sözleşmenin tarihi,

- Taraflar,

- Proje bilgileri,

- Sözleşme belgeleri/bileşenleri,

- Sözleşme süresi ve imza tarihi,

- Sözleşme bedeli,

- Hakediş,

- Sözleşmenin sona ermesi ya da askıya alınması,

- Maddi tazminatlar,

- İşverenin yüklenici ödemelerinden tuttuğu teminatlar.

İnşaat sözleşmeleri projelerin kanunen tanımlanmasının yanı sıra teknik açılardan da tanımlamaktadır (Yurt, 2005). Sözleşmelerde tarafların görev, yetki ve sorumlulukları; projelerde yönetim, plan, süre, maliyet, ödeme, detaylı çizimler, teknik özellikler ve tanımlanmış kalite gereksinimi; oluşabilecek herhangi bir anlaşmazlık durumunda ise yapılması ya da yapılmaması gereken her türlü işin ve davranışın belgelenmesi gerekmektedir (Komurlu; Arditi, 2017). Bu doğrultuda ihtiyaç duyulan sözleşme belgeleri şunlardır (Yalçın, 2004):

- Genel Şartname,

- İlave Koşullar ve Diğer Şartnameler,

- Teknik Şartnameler,

- Çizimler,

- Değişiklikler,

- Zeyilname.

Zamanla standart bir belge halini alan genel şartnameler, işin teknik boyutuyla ilgili maddeler bulundurmadan sözleşme taraflarının hak, yetki ve sorumluluklarını içermektedir (Yalçın, 2004). 
İlave koşullar, projeye özgü koşulları belirten ve genel şartname maddelerinde değişiklik ya da ekleme söz konusu olduğu durumlarda kullanılan belgelerdir. Yapısı genel şartname ile aynı olup daha geliştirilmiş ve özelleştirilmiş bir uzantısıdır (Kurt, 2005). Fiziksel ortamdan etkilenme ve araziye bağımlılık inşaat projelerinin öngörülemeyen koşullardan etkilenme ihtimalini artırmaktadır. İlave koşullar bu açıdan önem taşımaktadır. Genel şartname birçok proje için temel bir doküman iken, ek koşullar her projenin kendine özgü koşullarını içerir (Yalçın, 2004).

Teknik şartnameler, çizimlere ek olarak projelerin malzeme, işgücü, ekipman, uygulanacak işler ve yapılış şekli gibi nitel özelliklerini içeren dokümanlardır. Yazılı olarak ya da çizim ile gösterilebilirler (Yalçın, 2004). Uygulamada kullanılacak teknikler, taşıma sistemleri, çalışma prensipleri gibi bilgileri içerdiği için bilgili, tecrübeli, teknolojik gelişmeleri takip eden kişilerin bu dokümanları hazırlaması daha doğru olacaktır.

Çizimler, kağıt üzerinde projenin özelliklerinin fiziksel ve görsel olarak anlatıldığı dokümanlardır. İşin gerçekleşmesi, özellikleri bilinen tasarımın teknik şartnamelerde belirtildiği yöntemlerle genel şartname ve ilave koşul prosedürlerine uygun olarak hayata geçirilmesidir. Çizimler dokümanının içeriğinde genel bilgiler ve iş sahası çizimleri ile strüktürel, mimari, tesisat, ssıtma-havalandırma-klima, elektrik vb. çizimleri bulunmaktadır.

Değişiklikler, sözleşme imzalandıktan sonra işverene şartlarda değişiklik hakkı sunan yazıı ı dokümanlardır. Öngörülemeyen sebeplerle işin kapsamı, sözleşme bedeli, yapım tekniği, malzeme, sözleşme süresi gibi konularda değişiklik olabilir. Bunun yanı sıra çizimler ve şartnamelerdeki hataları ve eksikleri düzeltmek için de yapılabilir (Yurt, 2005). İyi yönetilemeyen değişiklikler ve gecikmeler, değişiklik taleplerine ve anlaşmazlıklara yol açmaktadır (Komurlu, 2018). Bu yüzden tarafların bunları doğru şekilde belgelemesi ve saklaması gerekmektedir.

Zeyilname, ihale dokümanlarında teklifler açılmadan önce yapılabilecek değişikliklerdir. Bu değişiklikler işin gerçekleştirilmesini etkileyebilecek maliyet hataları, teknik hatalar ya da yöntemle ilgili olabilir (Yalçın, 2004).

Taraflardan birinin sözleşmeyi ihlal etmesi durumunda yasalar iki ana çözüm öngörmektedir. Bu çözümler, sözleşmeyi ihlal eden tarafın karşı tarafta oluşabilecek zararı ödemesi ve mahkeme kararı ile belirlenen özel yaptırımlardır. Yapım projelerinde özel yaptırımların uygulanması zordur bu yüzden zararın maddi olarak karşılanması daha çok kullanılır (Kurt, 2005).

$\mathrm{Bu}$ belgeler ile işverenin hayalinde canlandırdığı projenin gerçekleşmesi için tasarım aşamasından teslimine kadarki tüm sürecin planlanması ve organizasyonu yapılarak risk en aza indirgenebilir. Belgelerdeki herhangi bir eksiklik ya da yapılan hatalar taraflar arasında sorunların çıkmasına sebep olur. Sorunlar çözülemezse anlaşmazlıklara dönüş̧mektedir.

\section{3. İnşaat Sektöründe Uyuşmazlık Kavramı ve Sebepleri}

Arıcı'ya göre çatışma "En az iki taraf arasında birbirinden farklı hedeflere, diğer tarafı engelleyecek şekilde ulaşmaya çalışmaktan doğan ifade edilmiş mücadele" olarak tanımlanmıştır (Arıc1, 2012). Uyuşmazlıklar çatışmaların çözülemeyip giderek artması sonucu oluşurlar ve genellikle tarafsız bir kişi ya da kurumun araya girmesi ile çözülürler (İlter, 2010).

Projenin başarısını olumsuz etkileyen faktörlerden biri de uyuşmazlıklardır. Çünkü uyuşmazlık durumunda taraflar kendi çıarlarını gözetmektedir ve kimin haklı kimin haksız olduğunu kanıtlamak için üçüncü kişiler ya da kurumlar eklenmektedir. Dolayısıyla baştaki çatışmanın potansiyel maliyeti artar, süresi uzar ve projenin performansı düşer. Bu da tarafların iş ilişkilerini zedeler ve prestijlerinde sarsılmaya sebep olabilir (İlter; Dikbaş, 2011).

Literatürde inşaat sektöründe uyuşmazlık sebepleri ile ilgili birçok liste bulunmaktadır. En kapsamlı liste Kumarashwamy (Kumaraswamy, 1998) ile Chan ve Suen (Chan; Suen, 2005) tarafından yapılmıştır. Bu listeye göre; yapılan değişiklikler, ödemeler, süre uzatımı, risklerin taraflar arasındaki dağılımı, sözleşme hükümleri ve iş tanımında belirsizlikler, yapılan işlerin kalitesi, katılımcıların şartnameleri farklı yorumlaması, yetersiz hukuk bilgisi, bilgi paylaşım eksikliği, tasarım-mühendislik hataları, gerçekçi olmayan talep ve beklentiler uyuşmazlı̆̆ın başlıca sebeplerini oluşturmaktadır. Bir diğer uyuşmazlık sebebi de inşaat sektöründeki belirsizlik ve risklerdir.

Herhangi bir belirsizlik durumunda, projenin olumlu ya da olumsuz etkilenmesine risk denir (Kömürlü; Memioğlu, 2018). Karmaşı ve heterojen yapıdaki inşaat sektöründe risk faktörü oldukça yüksektir. İnşaat projelerinin hedeflenen süre, maliyet ve kalitede tamamlanabilmesi için oluşabilecek risk faktörlerini en aza indirgemek gerekmektedir. İşin gerçekleştirilmesini sağlayan sözleşmeler, risk faktörünü en aza indirgeyen belgelerdir (Kurt, 2005). Sözleşmelerin hazırlanması kadar yönetimi de

74 | P a g e 
önemlidir. Bir projede oluşabilecek riskler belirlenip zamanında müdahale edilirse, risk faktörü azaltılarak proje, hedeflenen maliyet, süre ve kalitede tamamlanabilir.

Uygulamada genelde taraflar riski karşı tarafa devretmektedir. Ancak bu bir çözüm değildir. Sorumluluk, riski en az maliyet ile en iyi kontrol ederek yönetebilecek tarafa verilmelidir (Korkmaz, 2004). Taraflar, risk faktörünü gerçekleşme ihtimalinin yüksek olması ya da gerçekleştiğinde maddi zararın fazla olması sebebiyle üçüncü şahıs olan sigorta şirketlerine devredebilir. Bu da oldukça sık kullanılan bir yöntemdir. Ancak ülkemizde tüm risk kaynakları da sigorta yapılamamaktadır. Sigorta şirketleri de risklerin kaynağı, gerçekleşme ihtimali, finansal kayıp ile ilgili bir değerlendirme yapar ve maddi hasarın fazla olacağı durumlarda sorumluluk almak istemezler.

\section{4. İnşaat Sözleşmelerinde Uyușmazlık Çözüm Yöntemleri}

İnşaat sektöründe uyuşmazlıklar, projenin maliyetini, süresini uzatır ve istenen kalitede tamamlanmasını engeller. Oluşan bu sorun kısa sürede doğru kararlarla çözülemediğinde süreç aksayarak projenin durmasına sebep olurken, şirketlerin prestijlerine de zarar verir. Taraflar sürecin işleyişinin devam etmesi için sorunları en kısa sürede çözüme ulaştırmalıdır. Uyuşmazlıkların kolay ve sağlıklı çözülebilmesi doğru yöntemi seçmekle mümkündür. İlter'in (İlter, 2010) çalışmasında uyuşmazlık çözüm yöntemleri 2 ana başlık altında incelenmiştir. Tablo 1 bu veriler esas alınarak düzenlenmiştir.

Tablo 1: Uyuşmazlık Çözüm Yöntemlerinin Sınıflandırılması (İlter, 2010)

\begin{tabular}{|c|c|c|c|c|c|c|c|c|}
\hline \multicolumn{9}{|c|}{ Uyuşmazlık Çözüm Yöntemleri } \\
\hline \multicolumn{2}{|c|}{$\begin{array}{c}\text { Resmi } \\
\text { Yöntemler }\end{array}$} & \multicolumn{7}{|c|}{ ADR Yöntemleri } \\
\hline \multirow[b]{3}{*}{ 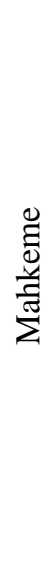 } & \multirow[b]{3}{*}{ 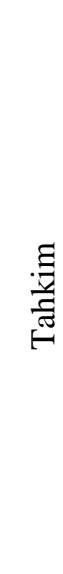 } & \multicolumn{2}{|c|}{$\begin{array}{l}\text { Karara } \\
\text { Dayalı }\end{array}$} & \multicolumn{5}{|c|}{ Anlaşmaya Dayalı } \\
\hline & & \multirow[b]{2}{*}{ 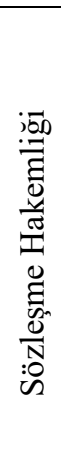 } & \multirow[b]{2}{*}{ 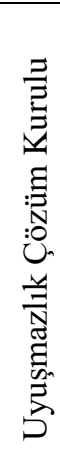 } & $\begin{array}{l}\text { Tarafsız } \\
\text { kissi yok }\end{array}$ & \multicolumn{4}{|c|}{ Tarafsız kişi var } \\
\hline & & & & 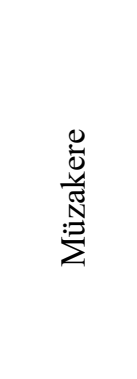 & 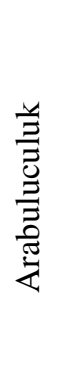 & 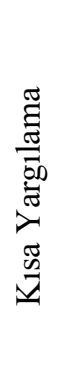 & 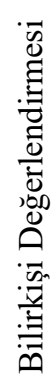 & 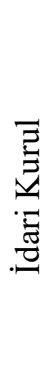 \\
\hline
\end{tabular}

Uyuşmazlık çözüm yöntemleri resmi yöntemler ve alternatif çözüm yöntemleri (ADR - Alternative Dispute Resolution) olmak üzere iki grupta incelenmektedir. Resmi yöntemler mahkeme ve tahkimdir. Çözüm süreci resmi yöntemlerin bürokratik yapısından dolayı uzun süreli ve maliyetlidir. Kazan-kaybet anlayışı olduğu için taraflar kendi çıkarları doğrultusunda hareket ederek rekabeti arttırır. Bu da tarafların birbirlerine olan güvenlerini sarsarak iş ilişkilerini zedeler. Bu olumsuzluklara rağmen kararlar bağlayıcı ve kesin hükümlü olduğu için resmi yöntemler Türk inşaat sektöründe sıkça kullanılmaktadır.

Alternatif uyuşmazlık çözümünde (ADR) ise tarafsız üçüncü bir kişi ya da kurum sürece dahil olarak, tarafların karşılıklı iletişim kurmalarına ve sorunun çözümünü kendilerinin bulmalarına ortam hazırlarlar. Uzlaşılamayan konularda ise olayın özelliklerine ve şartlarına göre uygun çözüm önerileri getirirler. ADR yönteminde çözüm süreci esnektir ve taraflar isteği doğrultusunda süreci yönlendirebilir. Taraflar sorunu çözme odaklıdır ve kazan-kazan anlayışı bulunmaktadır. Bu yüzden ADR dostane bir çözüm yöntemi olup tarafların iş ilişkileri korunmaktadır. Çözüm süreci resmi yöntemlere göre daha az maliyetli ve daha kısa sürelidir ancak bağlayıcılığı bulunmamaktadır. Türk inşaat sektöründe kullanımı giderek artmaktadır (İlter, 2010). 


\section{Sonuç}

Tasarım aşamasından projenin tamamlanmasına kadar tüm süreçlerin belirsizliklerle dolu olduğu inşaat sektörü, heterojen bir yapıda olup birçok iş kolunu bir arada çalışmasını gerektirir. Bu yüzden projede planlama, organizasyon ve paydaşların görev tanımlarını iyi belirlemek gerekmektedir. Sözleşmeler, karşılıklı ilişkileri düzenleyen, tarafların hak, yetki ve sorumluluklarının belirtildiği hukuki belgelerdir. Projenin hedeflenen maliyet, süre ve kalitede tamamlanmasını sağlayan sözleşmelerin doğru ve tam uygulanması önemlidir. Bu uygulama, sözleşme yönetimi ile sağlanır.

Sözleşmelerin, imzalanma öncesinde karşılıklı müzakere edilmesi, yanlış anlaşılmalarla muğlaklıkların azaltılması yönünde büyük katkı sağlar.

İnşaat projeleri büyüklükleri ve karmaşıklıkları dolayısıyla çok çeşitli risklere maruz kalırlar. Firmaların risk kaynaklarını iyi tanımlamaları ve bunlara yönelik stratejiler geliştirmeleri yanında sözleşmenin de risk dağılımını adil bir şekilde tariflemesi projenin başarısı için önemlidir.

Her proje, öngörülemeyen nedenlerle değişikliğe maruz kalmaktadır. Bir projenin başarısı, çoğu zaman, sözleşmenin değişiklik yönetimini nasıl gerçekleştirdiğiyle alakalıdır. Değişiklikler, süre uzamasına ve/veya maliyet artışına sebep olur. Değişiklik yönetimi sözleşmede doğru ve yeterli seviyede tanımlı değilse, uyuşmazlık ortaya çıkar. Uyuşmazlık çözümlerinde doğru yöntemi uygulamak süreyi kısaltıp ve maliyeti azaltırken aksi durum uygulamada aksamalara sebep olarak süreyi ve maliyeti arttırır, ilişkileri zedeleyerek şirket prestijine zarar verir.

Çalışmanın inşaat alanında bu konu ile ilgilenen kişi, kurum ve kuruluşlara bilgi sağlaması ve konuyla ilgili çalışma yürüteceklere 1şık tutması amaçlanmıştır.

\section{Kaynaklar}

Arıc1, Y., (2012). Inşaat Sektöründe ADR (Alternatif Uyuşmazlık Çözüm Yolları) Kullanımı ve Seçim Kriterlerinin Kamu ve Özel Sektör Açısından Incelenmesi, Yüksek Lisans Tezi, İ.T.Ü. Fen Bilimleri Enstitüsü, Mimarlık Anabilim Dalı, İstanbul, Türkiye.

Chan, E. H. W., \& Suen, H. C. H., (2005). Dispute Resolution Management for International Construction Projects in China, Management Decision, vol. 43, no. 4, pp. 589-602. doi: 10.1108/00251740510593576

Gedik, S. E. (2003). Marmara Depremi Acil Yeniden Yapılandırma (MEER) Projesinde FIDIC Esasl Inşaat Sözleşmesiyle Proje Yönetimi, Yüksek Lisans Tezi, İ.T.Ü. Fen Bilimleri Enstitüsü, İnşaat Mühendisliği Anabilim Dalı, İstanbul, Türkiye.

İlter, D. (2010). Inşaat Projelerinde Uyuşmazlık Çözüm Yöntemi Seçimi İçin Çok Kriterli Karar Verme Modeli, Doktora Tezi, İ.T.Ü. Fen Bilimleri Enstitüsü, Mimarlık Anabilim Dalı, İstanbul, Türkiye.

İlter, D., \& Dikbaş, A. (2011). Uyuşmazlık Çözüm Yöntemi Seçimi İçin Bir Karar Verme Yaklaşımı, ITÜ Dergisi/a Mimarlık, cilt: 10, sayı: 1, sayfa:165-176.

Komurlu, R. (2018). H. Öktem (ed.), Causes and Effects of Change Orders in Construction Projects: An Analysis for Effective Change Order Management, Current Approaches in Engineering and Architecture (pp. 1-8). Ankara, Turkey: Strategic Researces Academy (SRA) Academic Publishing, ISBN: 978-605-69047-2-1

Komurlu, R., \& Arditi, D. (2017). The Role of General Conditions Relative to Claims and Disputes in Building Construction Contracts, International Journal of Contemporary Architecture "The New ARCH”, vol. 4, no. 2, pp. 27-36. doi: 10.14621/tna.20170203

Korkmaz, A. (2004). Teklif Verme Sürecinde Olan Yükleniciler Iç̧in Inşaat Sözleşmelerinde Risk Değerlendirme, Yüksek Lisans Tezi, İ.T.Ü. Fen Bilimleri Enstitüsü, İnşaat Mühendisliği Anabilim Dalı, İstanbul, Türkiye. 
Kömürlü, R., \& Memioğlu, C. (2018). Maliye ve Finans Araştırmaları. Ö. Ülger (ed.), İnşaat Firmaları İçin İhale Aşamasında İnşaat Risklerinin Değerlendirilmesi (s. 65-77). Türkiye: İksad Yayınevi, ISBN: 978-605-7923-66-0

Kumaraswamy, M. M. (1998). Consequences of Construction Conflict: A Hong Kong Perspective, Journal of Management in Engineering, vol. 14, no: 3, pp. 66-74.

Kurt, S. (2005). Yapı Üretiminde Sözleşme Yönetimi ve Uluslararası Bir İnşaat Projesinin Sözleşme Yönetimi Sürecinin Incelenmesi, Yüksek Lisans Tezi, İ.T.Ü. Fen Bilimleri Enstitüsü, Mimarlık Anabilim Dalı, İstanbul, Türkiye.

Öcal, M. E. (2014). İnşaat Projelerinde Sözleşme Yönetimi, İstanbul, Türkiye: Birsen Yayın Dağıtım Ltd. Şti., 1. Baskı, ISBN: 978-9755116129.

Timurlenk, İ. (2018). Türkiye'de İnşaat Proje Yönetim Firmalarının Projeleri Yönetim Anlaylşl ve Erp Sistemlerinin Proje Yönetimine Sağladı̆̆ı Katkılarının Analizi, Yüksek Lisans Tezi, İ.T.Ü. Fen Bilimleri Enstitüsü, İnşaat Mühendisliği Anabilim Dalı, İstanbul, Türkiye.

Yalçın, H. (2004). A.B.D. ve Türk İnşaat Sektörlerindeki Standart Sözleşme ve Genel Şartnamelerin Karşılaş̧tırılması, Yüksek Lisans Tezi, İ.T.Ü. Fen Bilimleri Enstitüsü, Mimarlık Anabilim Dalı, İstanbul, Türkiye.

Yurt, A. (2005). Sözleşme Yönetimi, Yüksek Lisans Tezi, İ.T.Ü. Fen Bilimleri Enstitüsü, Mimarlık Anabilim Dalı, İstanbul, Türkiye. 